\title{
Assessment of Meteorological Drought for Ujjain District of Madhya Pradesh, India using Effective Drought Index and ArcGIS
}

\author{
Gaurav Sharma*, Chandra Kishor Kumar and Bhaskar Pratap Singh
}

Department of Farm Engineering, Institute of Agricultural Sciences, Banaras Hindu University, Varanasi-221005, Uttar Pradesh, India

*Corresponding author

\begin{abstract}
A B S T R A C T

\begin{tabular}{|l|}
\hline Key w o r d s \\
Drought intensity, \\
Drought magnitude, \\
EDI, ArcGIS \\
\hline Article Info \\
\hline Accepted: \\
07 April 2019 \\
Available Online: \\
10 May 2019 \\
\hline \hline
\end{tabular}

Drought is an abnormal condition resulting due to a decrease in rainfall. The occurrence of drought is unpredictable and causes unprecedented damage to the production of crop and livelihood. The present study has been conducted to assess the meteorological drought situation in Ujjain district using Effective Drought Index (EDI). For assessment six rain gauge station situated in the study area is selected. Out of which station namely Barnagar, Ghatiya and Tarana have maximum extreme drought event with 8, 7, and 3 respectively. The occurrence of severe drought event is high for Khachrod station with 30 events. Drought intensity is maximum for Barnagar station (-1.44) and minimum for Mahidpur station (-1.3) indicating variability in the availability of water. The rising trend of meteorological drought severity is found in the region. The surface feature of land also contributes to the frequent occurrence of drought in that region. The rainfall distribution is uniform although the runoff is affected due to the slope which resulting in accumulation in water low lying area i.e. Mahidpur station and hence the existence of less severe drought, on the other hand in a high elevated area where water does not accumulate like Barnagar station are affected by extreme drought situation.
\end{abstract}

\section{Introduction}

Drought is an insidious hazard of nature in many parts of the world. It originates from a persistent shortage of precipitation over a specific region for a specific period of time and has a conceptual and operational definition. Drought impact on some activity, group, or environmental sector depends on the extent of water shortage and ground conditions. The parameters indicating drought impacts include soil moisture depletion, reduction in stream flow, reservoir storage, lake levels and groundwater level (Dracup et al., 1980). However, when it occurs, it generally affects a broad region for a season or a year or for consecutive years. The arid areas are more prone to drought because the rainfall amount critically depends on a few rainfall events (Sun et al., 2006). The severity of drought-affected areas change gradually and regions of maximum intensity shift from season to season (Wilhite, 2000). Although several indexes were proposed for the analysis of propagation drought for assisting policymakers to address this phenomenon in 
advance, drought severity is considered a key factor as compared to others. Drought monitoring and forecasting are important tools for implementing appropriate drought mitigation strategies in order to reduce the impact of drought. The Effective Drought Index (EDI) in daily and monthly time step characterizes drought severity superior to any other index (Pandey et al., 2008). Morid et al., (2006) used EDI, which is able to detect the onset and spatiotemporal variation of drought consistently so the EDI was found to be more responsive to the emerging drought and hence preferred. Kar et al., (2016) studied the drought severity using EDI for Bundelkh and region and found a gradually increasing severity. Kumar et al., (2018) characterized metrological drought using effective drought index for Banswara district, Rajasthan. As the area under consideration is completely rainfed so variation in rainfall during monsoon period affects crop growth severely and there is a regular occurrence of drought. In this context, the given region is considered for meteorological drought assessment which helps hydrologist and agriculture planner for efficient planning during stress conditions.

\section{Materials and Methods}

\section{Study area}

The study area is located in Madhya Pradesh state in the west-central part of India and is north of the upper limit of the Vindhya mountain ranges. Located on the Malwa plateau, it is higher than the north Indian plains and the land rises towards the Vindhya Range to the south. Ujjain's coordinates are $23^{\circ} 10^{\prime} \mathrm{N} 75^{\circ} 46^{\prime} \mathrm{E}$ with an average elevation of $494 \mathrm{~m}$. The region is an extension of the Deccan Traps, formed between 60 and 68 million years a goat the end of the Cretaceous period. The city is on the bank of the river Shipra which flows into the nearby Chambal. Summers usually starts by the middle of
March which lasts up until late June. During which temperatures normally reach up to 45 ${ }^{\circ} \mathrm{C}$, with average maximum peaking in May with $41{ }^{\circ} \mathrm{C}$. Monsoon starts in late June and ends in late September. The average annual rainfall is $924.06 \mathrm{~mm}$. The base map for the study area is shown in Figure 1.

\section{Data availability}

The Daily rainfall records of 32 years for various stations in Ujjain district are obtained from State Data Centre, Water Resource Department, Government of India. Data period availability and geographical information of these stations are shown in table 1 and the location of various rain gauge stations is depicted in Figure 2.

\section{Effective drought index $(E D I)$}

Byun and Wilhite (1999) proposed Effective Drought Index $(E D I)$, is a reply and have the potential to deal with all of the limitations of SPI. EDI provides more information's: duration and severity of rainfall deficit, start and end of the drought period. Effective precipitation $(E P)$ that represents resources daily depletion of water is the base of concept $E D I$ (Morid et al., 2006). The original form of $E D I$ is computed with a daily time step using daily rainfall data. Smakhtin and Hughes (2007) modified his algorithm to be tested with monthly data.

Byun and Wilhite (1999) suggested the following equation for $E P$ :

$\mathrm{Epi}=\sum_{n=1}^{i} \frac{\sum_{m=1}^{m} \mathbf{P m}}{n}$

Where, $E P i=$ valid effective precipitation, $P m$ $=$ daily precipitation, $m=$ number of days before a specific day, $i=$ the number of days of the time window, $n$ =running from 1 till $i$ (Chhajer et al., 2015). 
$D E P=E P / M E P$

Where, $E P=$ effective precipitation for 365 days counting from a specific day, $M E P=$ the mean of effective precipitation, $D E P=$ deviation of $E P$ from $M E P$.

$E D I$ is calculated as,

$E D I=D E P / S D(E P)$

$S D(E P)=$ the standard deviation of each day's EP.

Ranks of EDI reflect drought conditions (Byun and Wilhite, 1999] indicate: extreme drought $(E D I \leq-2.0)$, severe drought $(-1.99 \leq$ $E D I \leq-1.5)$, moderate drought $(-1.49 \leq E D I$ $\leq-1.0)$ and near normal conditions $(-0.99 \leq$ $E D I \leq 0.99)$.

\section{Results and Discussion}

\section{Evaluation of meteorological drought characteristics}

Characterization of drought severity based on Effective Drought Index has been carried out and is used for evaluating the meteorological drought scenario in the Ujjain district. The temporal variation for various stations from drought perspective is depicted in Figure 3 to 8.

The declining EDI value observed from the analysis signifies an increasing drought severity for the study area. Drought characteristics include onset, termination, duration, and drought severity. Drought events occur at all the six rain gauge stations and the severity of which is given in Table 2 .

It has been observed that extreme drought events occurred at Barnagar, Tarana and Ghatiyastation (Table 2). Extreme drought event occurred maximum time i.e. 8 in
Barnagar station indicating highly water stress area. Severe drought events occur in Khachrod (30) for maximum number of times followed by Ujjain (19) and lowest at Tarana station (9). Moderate drought events occur at Mahidpur (50) for the maximum time and a minimum of 39 at Khachrod station. Drought duration is maximum for Khachrod (67) followed by Mahidpur (66), and Ujjain station (64).Drought severity in the study area as calculated by EDI is represented using ArcGIS 10.1 in Figure 9.

Drought intensity is maximum for Barnagar station (-1.44) and minimum for Mahidpur station (-1.3) indicating variability in the availability of water in the region. Hence precaution should be taken while mitigating so as to reduce drought impact in that region. The analysis using Effective drought index indicates that the occurrence of meteorological drought is frequent and severity of which differ from region to region. Drought intensity in the study area as calculated by EDI is represented using ArcGIS 10.1 in Figure 10.

Drought duration for most of the stations is nearby same thus indicating high water demand during crop growing season due to the requirement of water to meet the demand at the same time.

The topography of the study area that is elevation and regional variability in the magnitude of rainfall also contributes to the frequent occurrence of drought and an increase in its magnitude. The spatial variability in the magnitude of rainfall is depicted in Figure 11.

From EDI calculation it is clearly understood that Barnagar station is under extreme drought condition although it receives adequate rainfall in comparison with Mahidpur station. Thus from here, it is known 
that other than rainfall, the topography of study area also contribute to a drought-like situation. The contour map of the study area is shown in Figure 12.

Table.1 Data period availability and location of rain gauge station in study area

\begin{tabular}{|l|r|r|r|l|l|}
\hline Station & Latitude & Longitude & \multicolumn{1}{|l|}{ Elevation } & Mean & Selected Period \\
\hline Barnagar & 23.0504 & 75.3774 & 497 & 917.75 & $1985-2016$ \\
\hline Ghatiya & 23.3786 & 75.863 & 509 & 887.55 & $1985-2016$ \\
\hline Khachrod & 23.4216 & 75.2798 & 485 & 905.68 & $1985-2016$ \\
\hline Mahidpur & 23.4857 & 75.6545 & 486 & 874.77 & $1985-2016$, \\
\hline Tarana & 23.3375 & 76.0421 & 490 & 1000.25 & $1985-2016$ \\
\hline Ujjain & 23.1793 & 75.7849 & 494 & 958.34 & $1985-2016$ \\
\hline
\end{tabular}

Table.2 Drought severity, duration and intensity for different station of district Ujjain

\begin{tabular}{|l|r|r|r|r|r|r|}
\hline Station & Extreme & Severe & Moderate & Normal & $\begin{array}{c}\text { Drought } \\
\text { Duration }\end{array}$ & Drought Intensity \\
\hline Barnagar & 8 & 10 & 44 & 252 & 62 & -1.44 \\
\hline Ghatiya & 3 & 18 & 41 & 255 & 61 & -1.36 \\
\hline Khachrod & 0 & 30 & 39 & 241 & 67 & -1.37 \\
\hline Mahidpur & 0 & 16 & 50 & 249 & 66 & -1.3 \\
\hline Tarana & 7 & 9 & 44 & 262 & 59 & -1.39 \\
\hline Ujjain & 0 & 19 & 46 & 267 & 64 & -1.35 \\
\hline
\end{tabular}

Fig.1 Base map of study area

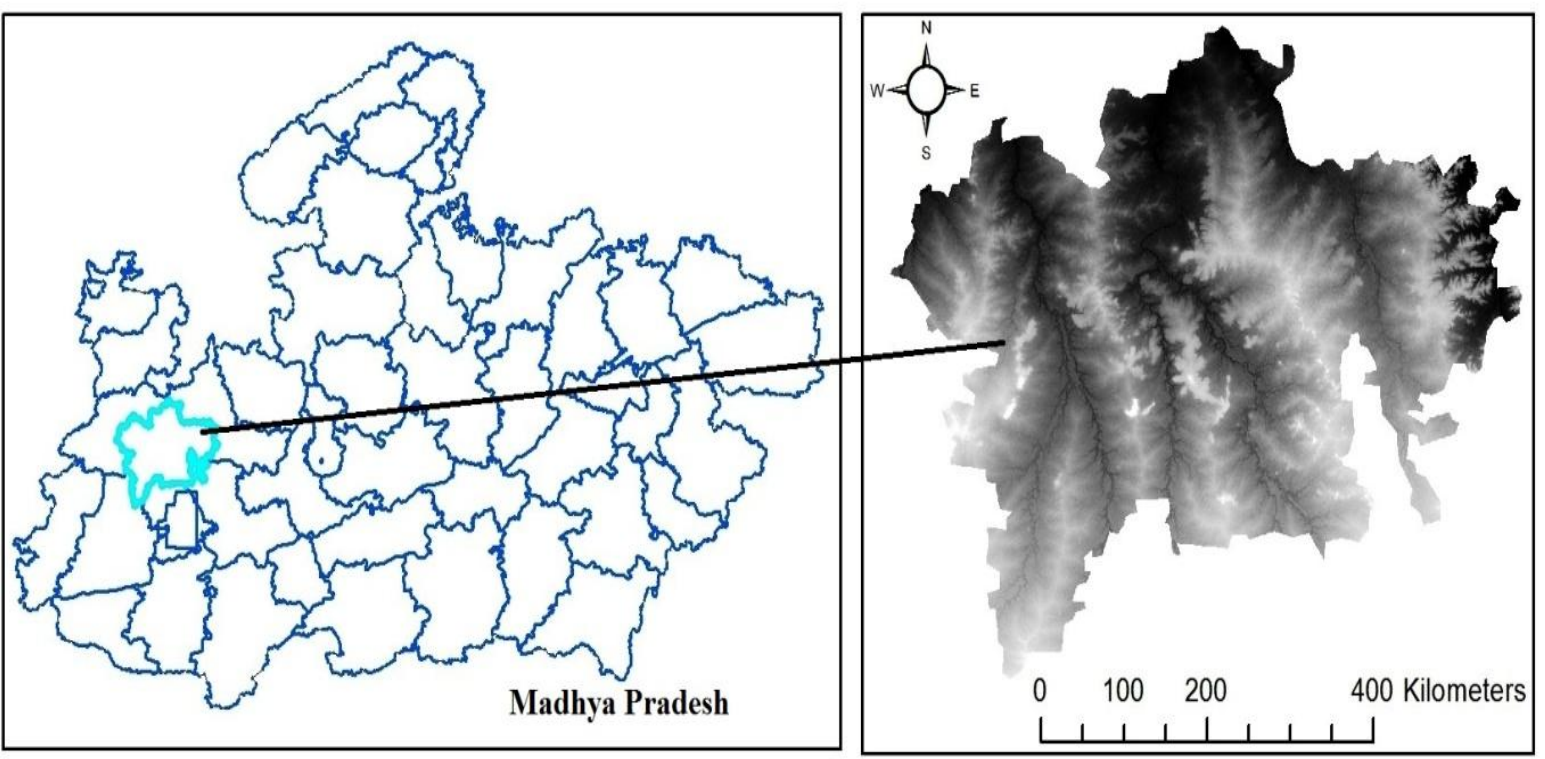


Fig.2 Location of rain gauge station in Ujjain district

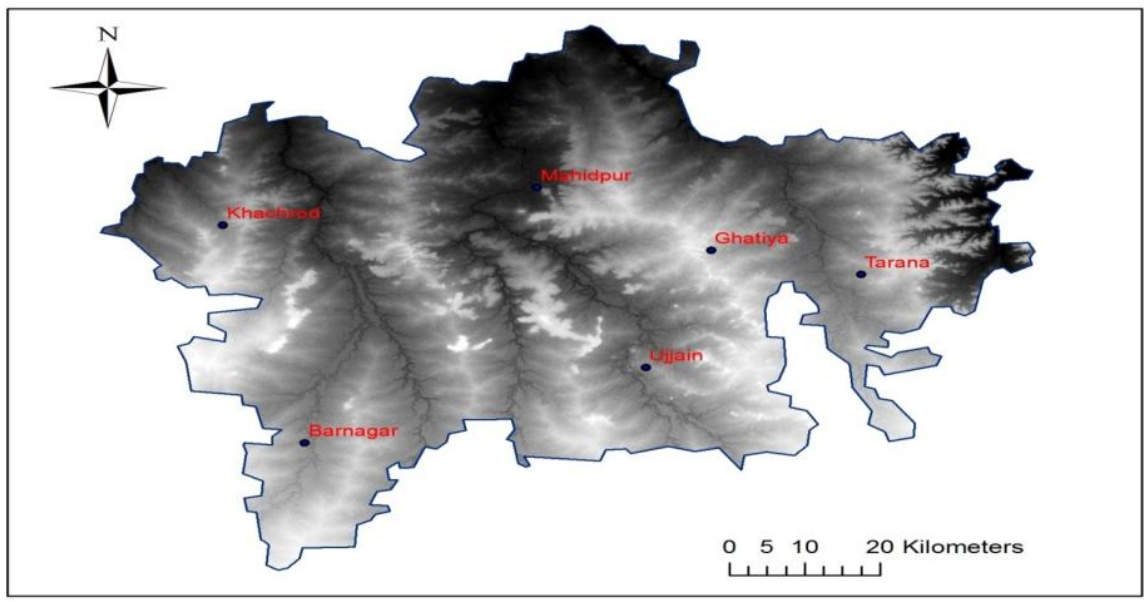

Fig.3 Temporal variation for Barnagar station

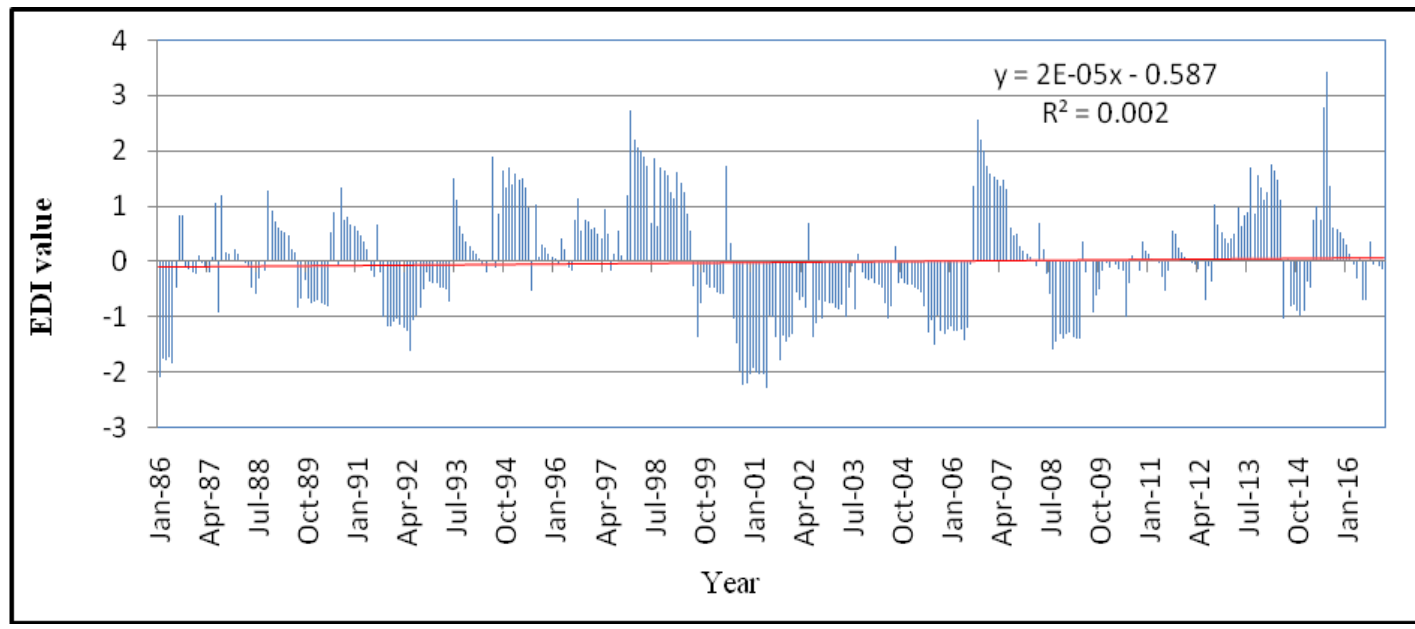

Fig.4 Temporal variation for Ghatiya station

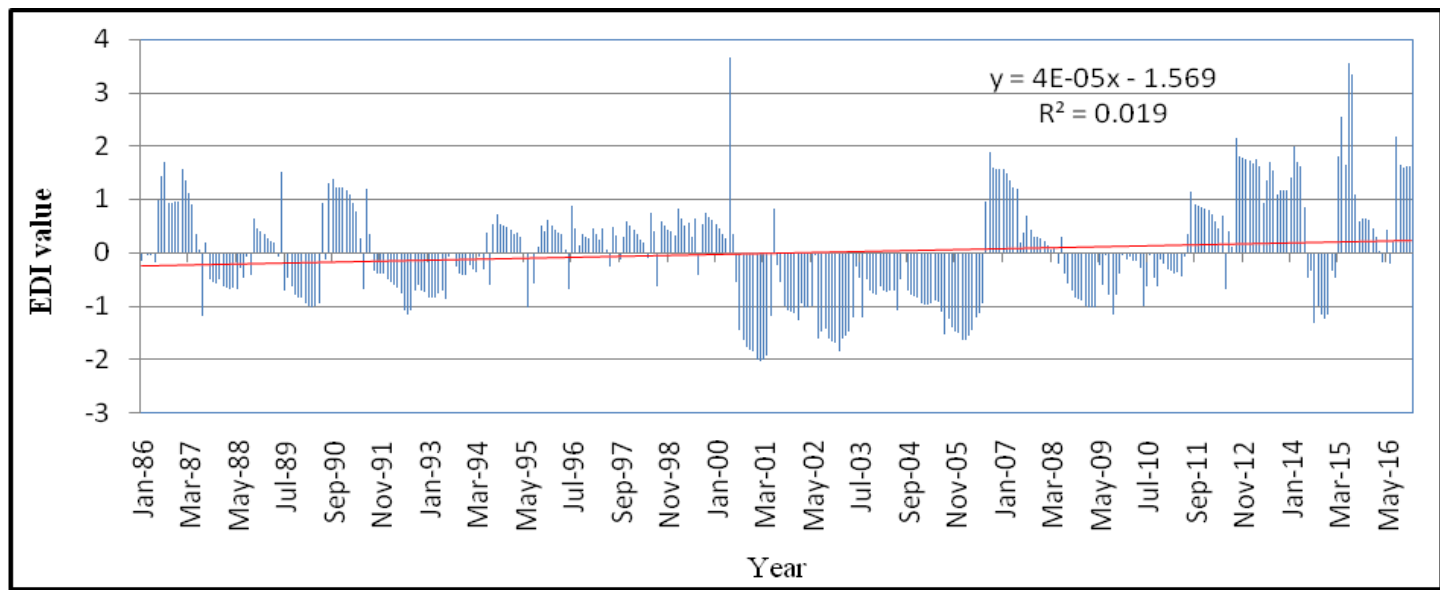


Fig.5 Temporal variation for Khachrod station

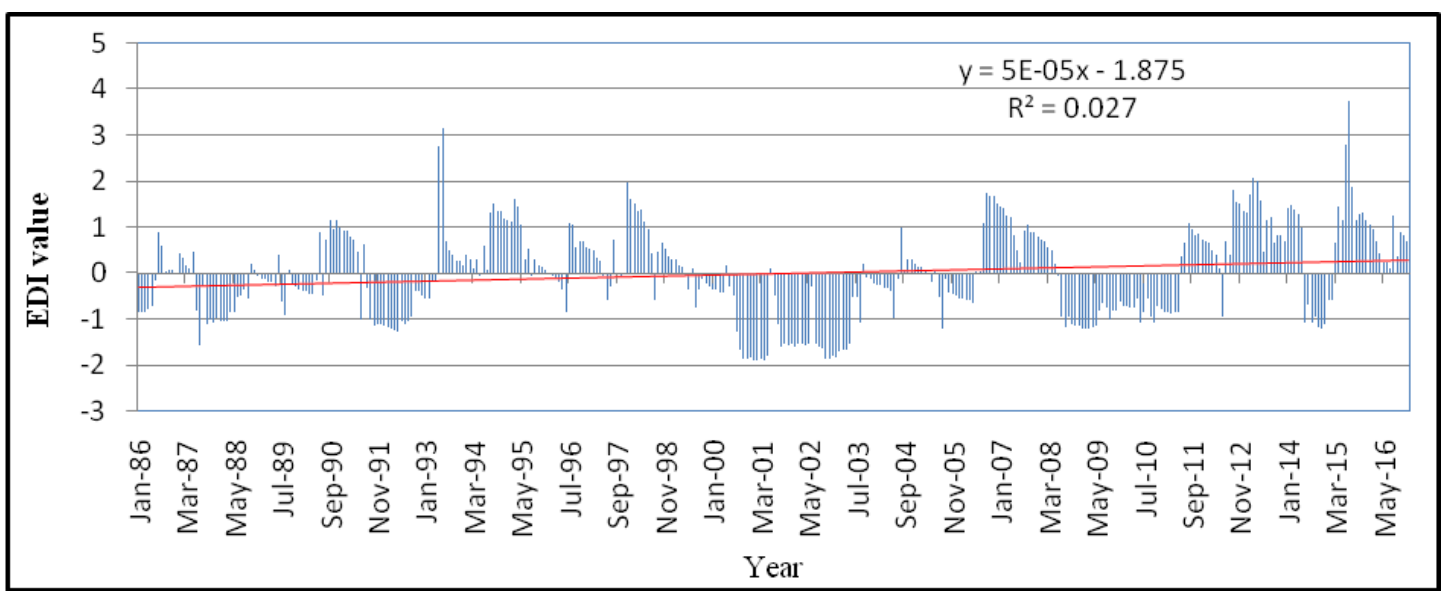

Fig.6 Temporal variation for Mahidpur station

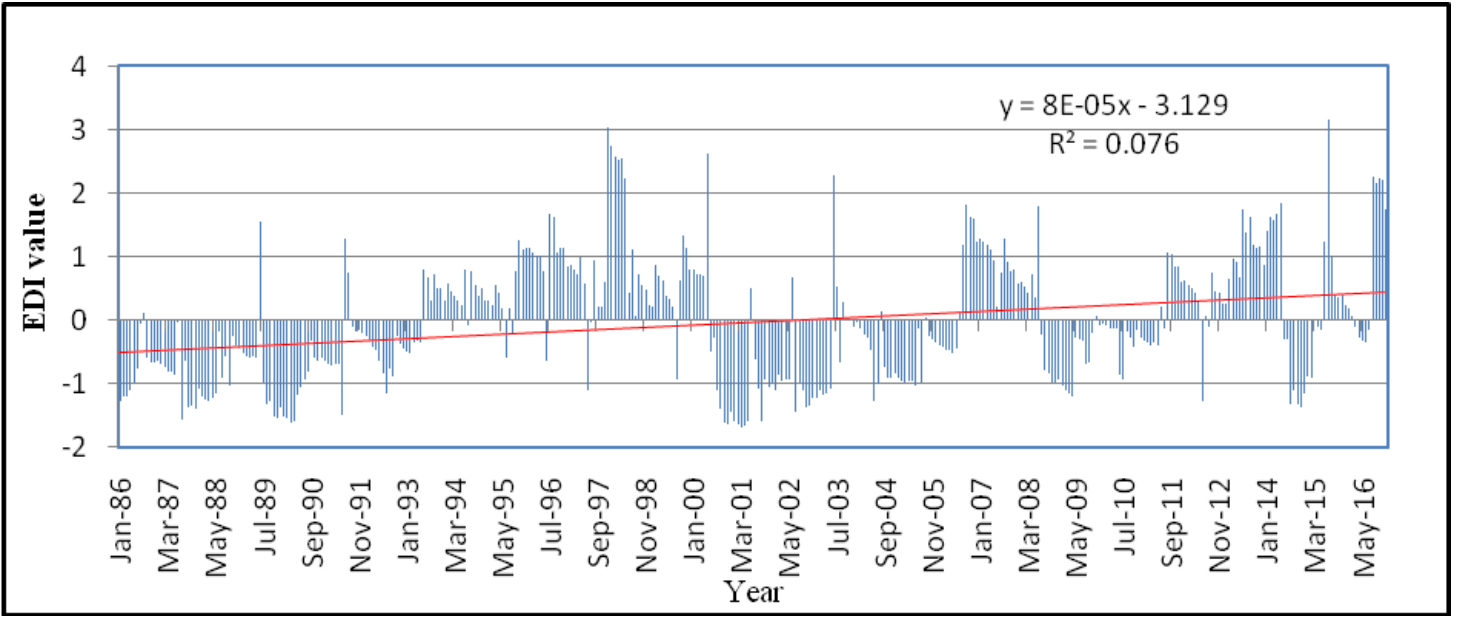

Fig.7 Temporal variation for Tarana station

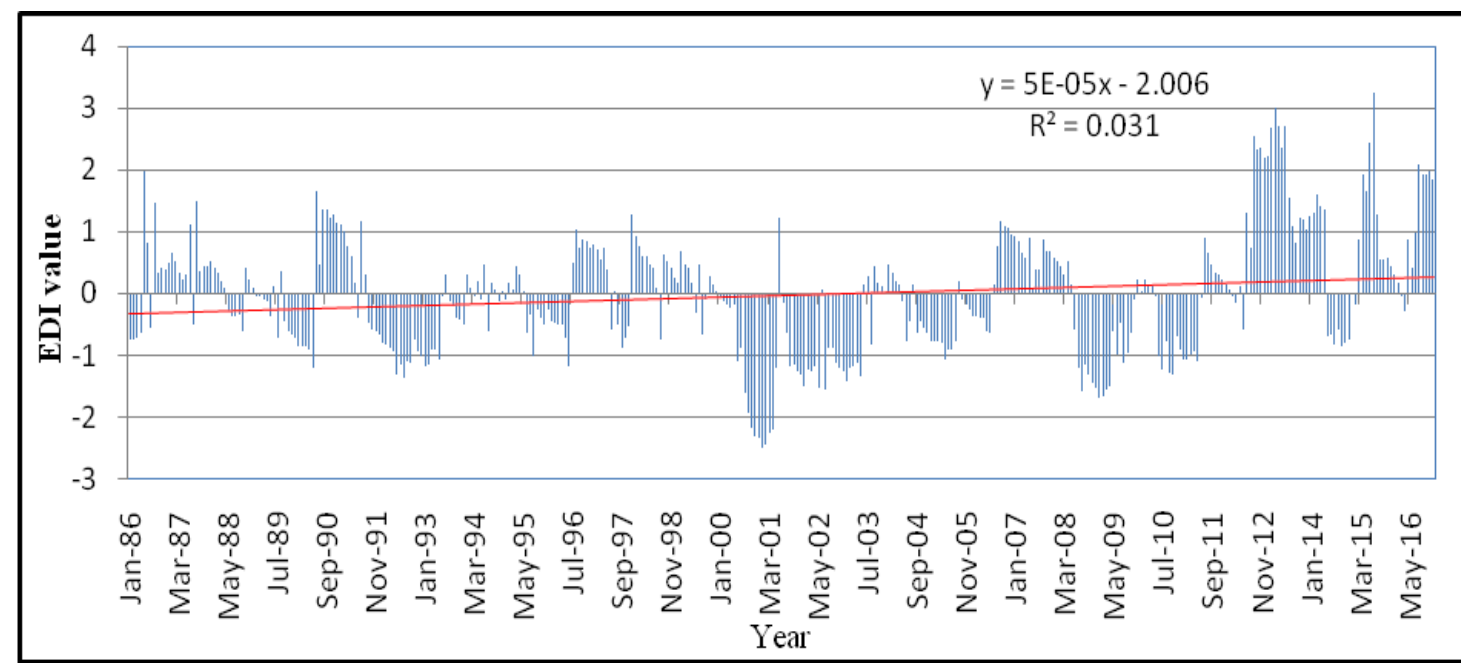


Fig.8 Temporal variation for Ujjain station

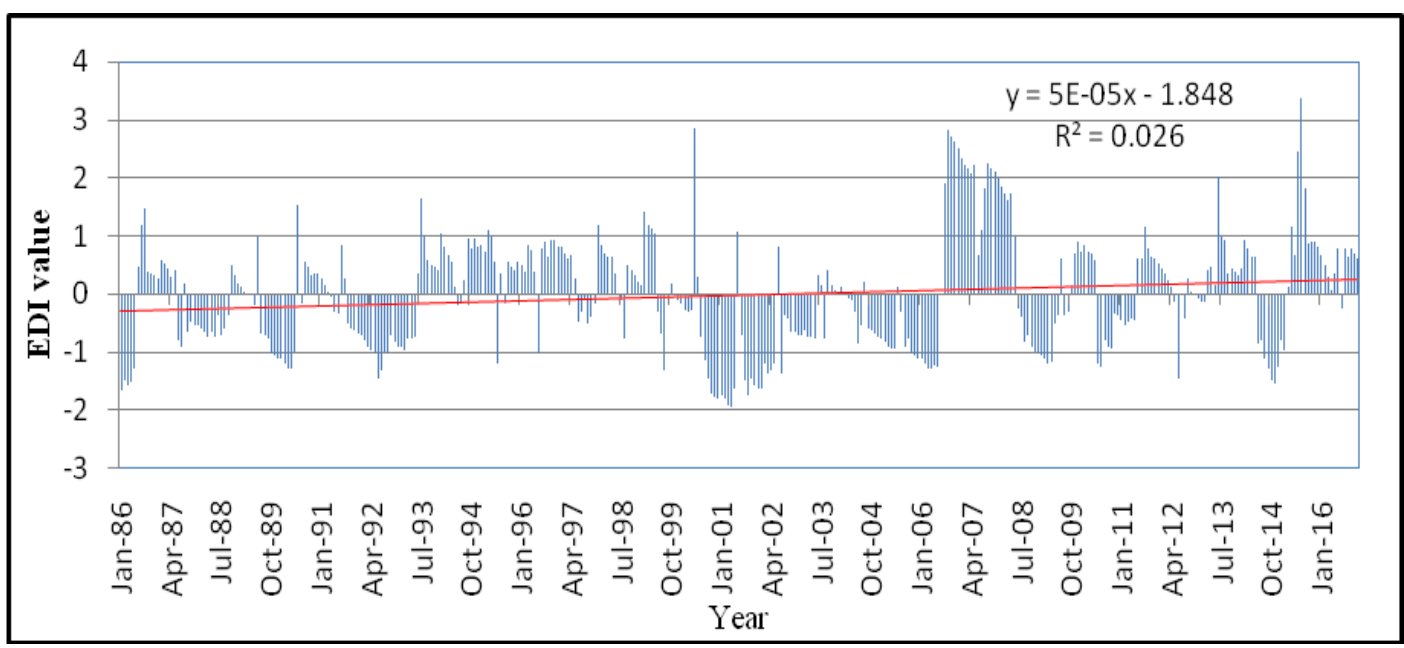

Fig.9 Drought severity map for the study area
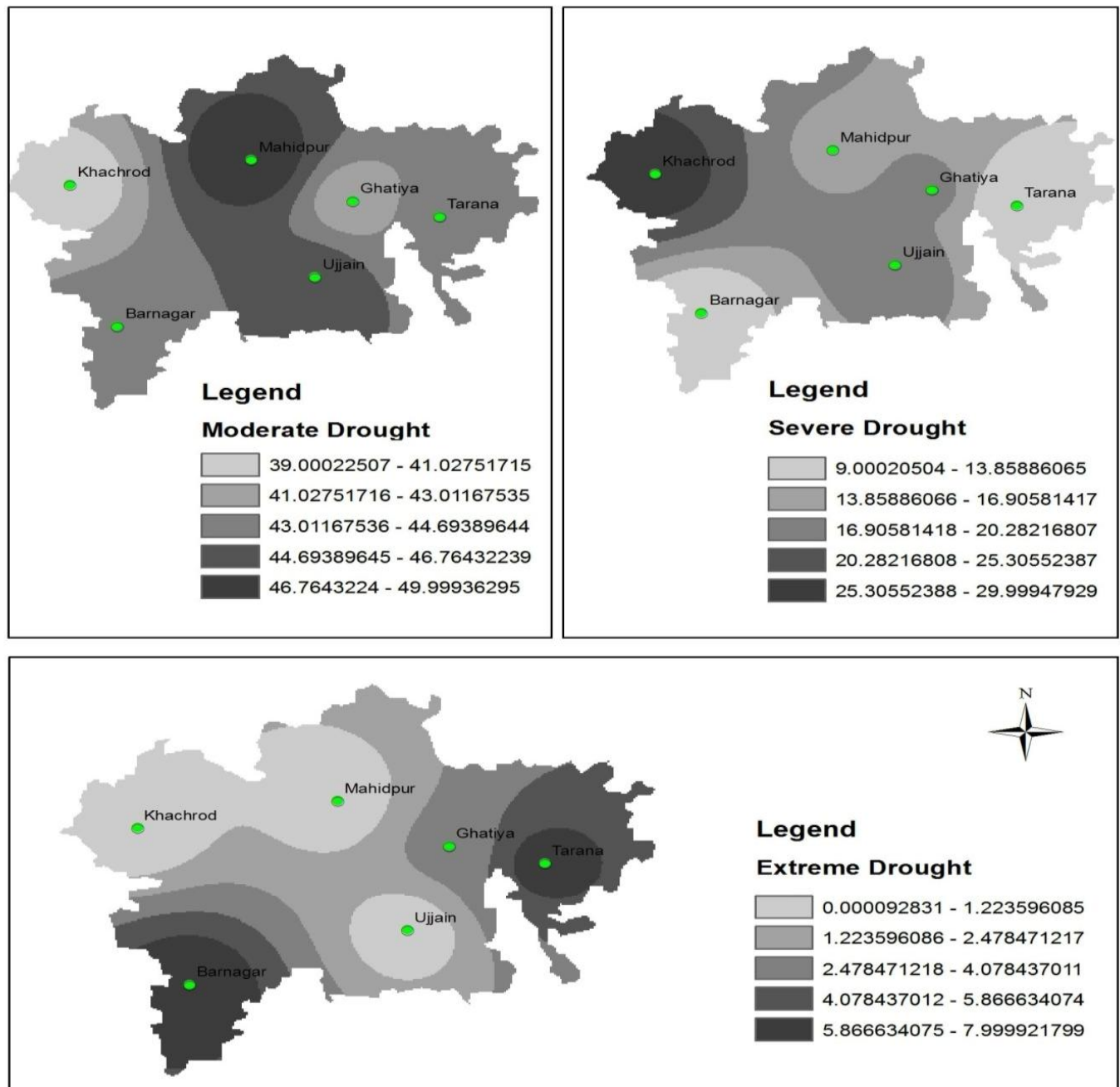

\section{Legend}

Extreme Drought

$0.000092831-1.223596085$

$1.223596086-2.478471217$

$2.478471218-4.078437011$

$4.078437012-5.866634074$

$5.866634075-7.999921799$ 
Fig.10 Drought intensity map for the study area

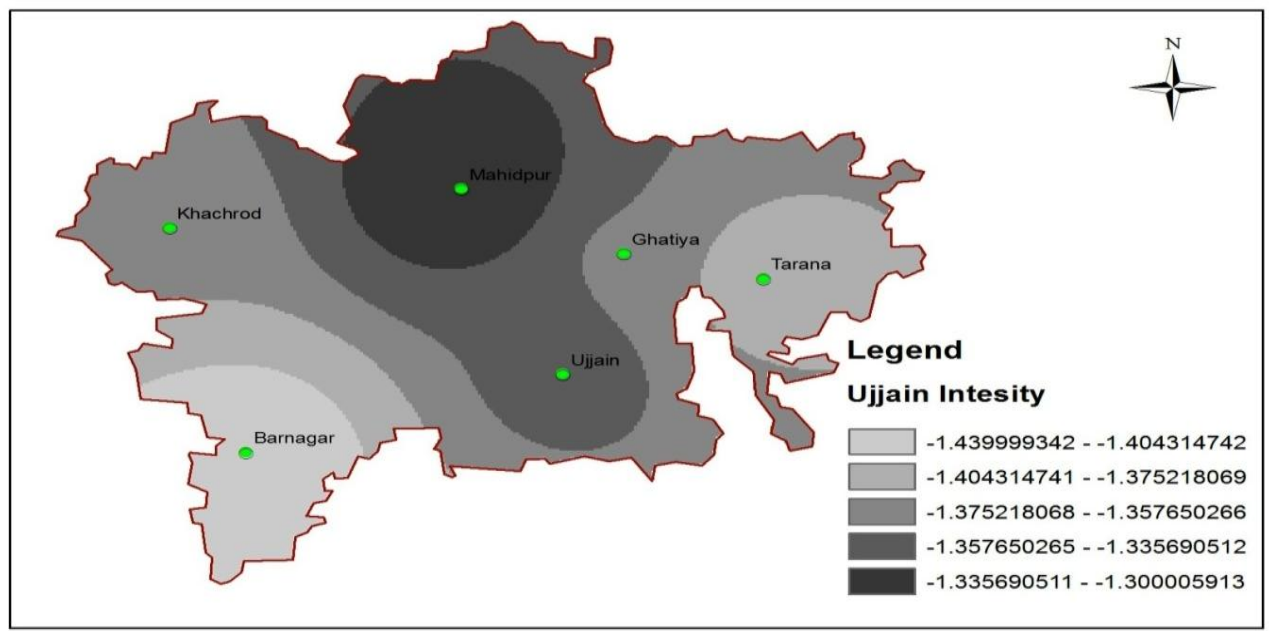

Fig.11 Average annual rainfall for the study area

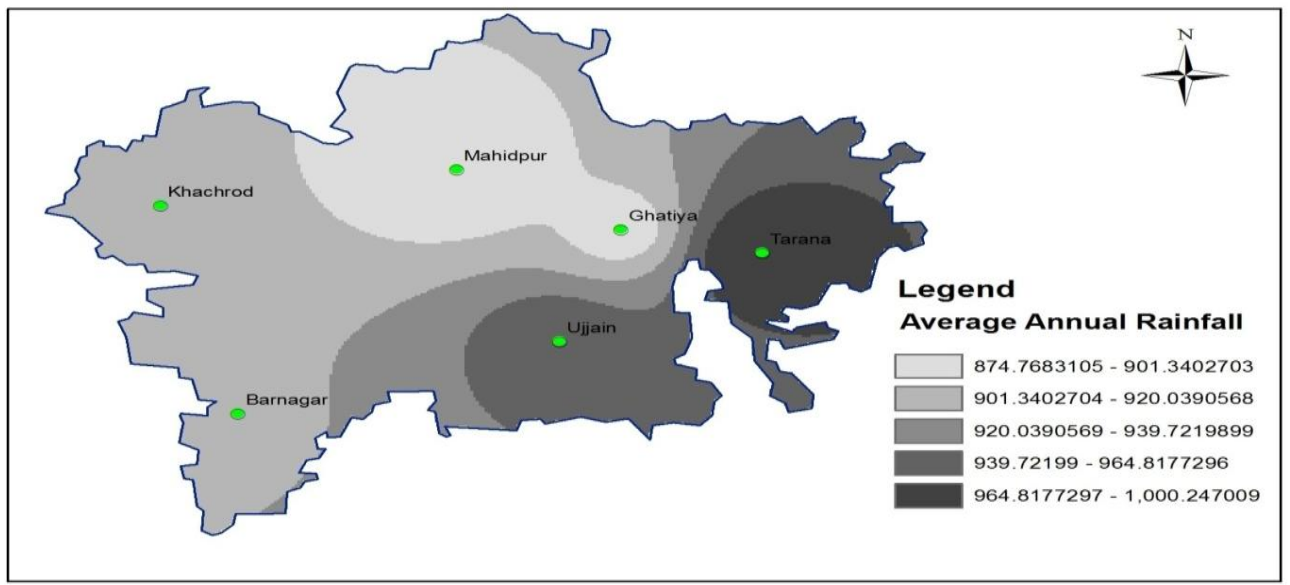

Fig.12 Contour map for the study area

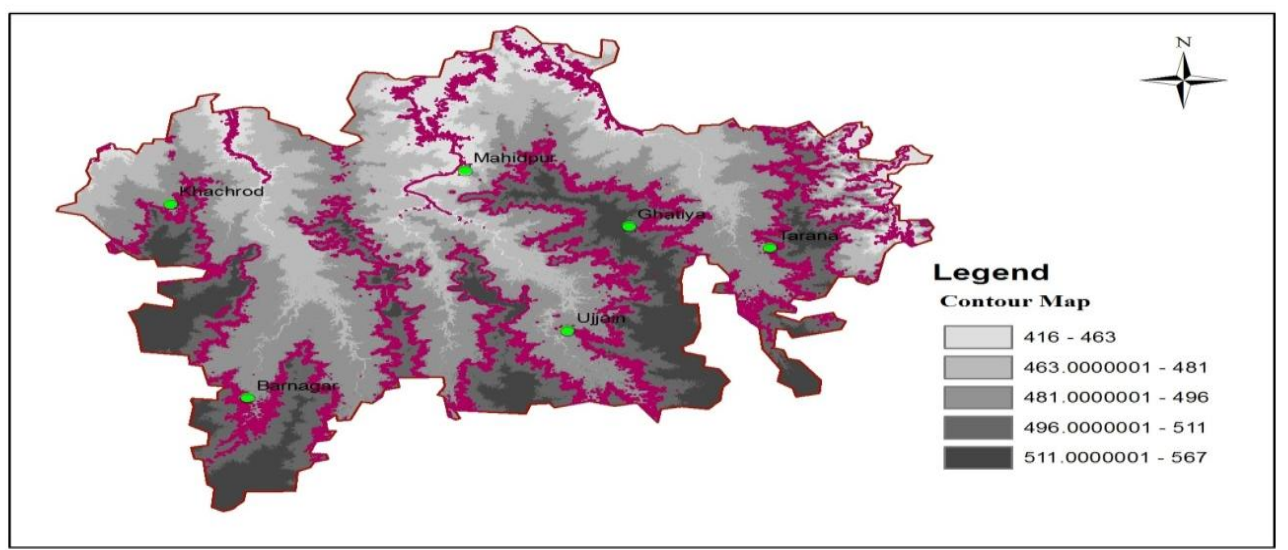


Barnagar station is located at a higher elevation in comparison to Mahidpur station indicating more accumulation of runoff water in the Mahidpur region. This further results in an availability of groundwater at Mahidpur and hence less affected by drought when the entire region is affected.

\section{References}

Byun, H.R., and Wilhite, D.A., 1999. Objective quantification of drought severity and duration. Journal of Climate. Vol. 12 p. 2747-2756.

Chhajer, V., Prabhakar, S., Prasad, R.C., 2015. Development of index to assess drought conditions using geospatial data a case study of Jaisalmer district, Rajasthan, India. Geo informatica Polonica. Vol.14. Iss. 1 p. 29-40.

Dracup, J.A., Lee, K.S and Paulson, E.G., 1980. On the definition of droughts. Water Resource Res., 16(2): 297-302.

Kar, S. K., Thomas, T and Singh, R. M., 2016. Assessment of drought characteristics for Dhasan basin in Bundelkh and region. International Journal of Agriculture, Environment and Biotechnology, 9(5): 897.

Kumar, C.K., Chandola, V.K and Kumar, R., 2018. Meteorological Drought Characterization Using Effective
Drought Index (EDI) for Banswara District (Rajasthan), India. Int.J.Curr.Microbiol.App.Sci. $\quad$ 7(09): 3407-3416.

Morid, S., Smakhtin, V and Moghaddasi, M., 2006. Comparison of seven meteorological indices for drought monitoring in Iran. International Journal of Climatology, 26(7): 971985.

Pandey, R.P., Dash, B.B., Mishra, S.K and Singh, R., 2008. Study of indices for drought characterization in KBK districts in Orissa (India), Hydrological Processes, 22(12): 1895-1907.

Smakhti, V.U and Hughes, D.A., 2007. Automated estimation and analyses of meteorological drought characteristics from monthly rainfall data. Environmental Modelling and Software. Vol. 22 p. 880-890.

Sun, Y., Solomon, S., Dai, A and Portmann, R.W., 2006. How often does it rain? J. Clim., 19(6): 916-934.

Wilhite, D.A., 2000. Drought as a natural hazard: concepts and definitions. Published in drought: a global assessment, I, edited by Donald A. Wilhite, Drought mitigation centre faculty publications, University of Nebraska - Lincoln, chap. 1, 3-18.

\section{How to cite this article:}

Gaurav Sharma, Chandra Kishor Kumar and Bhaskar Pratap Singh. 2019. Assessment of Meteorological Drought for Ujjain District of Madhya Pradesh, India using Effective Drought Index and ArcGIS. Int.J.Curr.Microbiol.App.Sci. 8(05): 604-612.

doi: https://doi.org/10.20546/ijcmas.2019.805.070 